\title{
Chronic Formaldehyde-Mediated Impairments and Age-Related Dementia
}

\author{
Junye Miao and Rongqiao $\mathrm{He}^{*}$ \\ State Key Laboratory of Brain and Cognitive Sciences, Institute of Biophysics, \\ Chinese Academy of Sciences, Beijing \\ China
}

\section{Introduction}

\subsection{Formaldehyde (FA) in the human environment}

FA $\left(\mathrm{H}_{2} \mathrm{CO}\right)$, the simplest aldehyde (Kilburn, 1994), existed in the pre-biological atmosphere of the primordial earth (Canuto et al., 1983) and is also present in the outer galaxies (Blair et al., 2008). FA is believed to have been the first organic molecule, being derived from photochemical reactions between simple gas elements in the primeval earth's atmosphere (Reaction 1) (Pinto et al., 1980; Canuto et al., 1983).

$$
\mathrm{CO}_{2}+2 \mathrm{H}_{2} \rightarrow \mathrm{H}_{2} \mathrm{CO}+\mathrm{H}_{2} \mathrm{O}(h v)
$$

FA is also a basic biological building block, and participates in the synthesis of amino acids such as glycine and alanine in aqueous medium (Miller, 1953; Sokolskaya, 1976; Sakurai\&Yanagawa, 1984). It is involved in the generation of carbohydrates via the formose cycle in bacteria (Kalapos, 1999). FA is believed to form complex organic molecules (Canuto et al., 1983) and play a key role in the process of evolution (Kalapos, 1999).

As reported by the U.S. Environmental Protection Agency (June 18, 2010), FA is present in products such as abrasive materials, plywood adhesives, insecticides, insulation and embalming fluids. Anthropogenic production of FA is mainly from power plants, petroleum refineries, coking operations, incineration, motor vehicle exhaust, and tobacco smoke (He et al., 2010). This simplest aldehyde has become one of the highest risk factors in the pollution of the human environment.

\subsection{Toxicity of exogenous formaldehyde and cognitive impairments}

Due to its high reactivity, FA leads to the formation of stable methylene bridges between nucleic acids and the amines of proteins (Conaway et al., 1996), resulting in crosslinking between nucleic acids and/or proteins and their subsequent polymerization (Kast et al., 2008). Both the amino-terminals of proteins and residues containing $\varepsilon$-amino and thiol groups, such as lysine, arginine, histidine, cysteine, tyrosine and tryptophan, are modifiable

${ }^{*}$ Corresponding Author 
targets of FA, and form methylol groups or Schiff-bases after modification (Metz et al., 2004). A number of reports have indicated that FA usually acts as a chemical crosslinker for biomacromolecules in cells. Exposure to FA at a concentration of $0.21 \mathrm{mM}$ for $6 \mathrm{~h}$ reduces the growth rate of human bronchial epithelial cells to $50 \%$ that of controls due to FA depression of RNA synthesis and the formation of both DNA single-strand breaks and DNA-protein crosslinks (DPCs) (Saladino et al., 1985). When cultured with FA at concentrations of 0.1-0.3 mM, human lung A549 cells, primary human nasal epithelial cells and DT40 cells undergo the process of DPC formation (Nakamura et al., 2007; Speit et al., 2008). Treatment of rat aorta endothelial cells with FA at $0.01-2.00 \mathrm{mM}$ promotes the formation of DPC, a potential risk factor in atherosclerosis (Yu\&Deng, 1998; Zhang et al., 2006). FA has also been shown to induce chromosomal aberrations (CAs) and sister chromatid exchanges (SCEs) in cultured cells (Conaway et al., 1996). It is worth noting that FA has biphasic effects on cell lines depending on its concentration: enhancing apoptosis, necrosis and even causing cell death at high concentrations $(>1 \mathrm{mM})$, while promoting cell proliferation at low dose (0.1 mM) (Tyihak et al., 2001).

Excess exposure to exogenous FA can induce carcinogenesis and cardiovascular dysfunction, possibly due to the formation of DPC (Shaham et al., 2003). Inhalation of FA vapor at concentration of up to $0.50 \mathrm{mM}$ can cause rhinitis, epithelial dysplasia, squamous metaplasia, and even squamous cell carcinomas in rodents (Swenberg et al., 1980). Similar results have also been observed in a study on monkeys exposed to FA at $0.20 \mathrm{mM}$ (Conaway et al., 1996). Tumor generation has been observed in humans when excess FA has been inhaled over a long period (Soffritti et al., 2002). In addition, oral administration of FA in drinking water at concentrations of $33.3 \mathrm{mM}$ and $166.5 \mathrm{mM}$ can cause hyperplasia, hyperkeratosis, erosion and/or ulcers in the alimentary system of rats (Conaway et al., 1996). Exposure to FA vapor also induces myocardical ischemia (Rety\&Marin, 1957), while rats infused with $0.12 \mathrm{mM}$ FA suffer cardiovascular attacks (Strubelt et al., 1990).

Studies on the relationship between exogenous FA and the immune system have indicated that exposure to FA promotes the response of cultured mast cells (Fujimaki et al., 1992), activates the immune system, and increases related antibodies in human sera (Patterson et al., 1986; Thrasher et al., 1990).

An overload of exogenous FA induces damage to the nervous system including changes in neurofilament proteins and demyelination (Perna et al., 2001). When exposed to FA, rats perform poorly at finding food in a maze, compared with controls (Pitten et al., 2000) and are also deficient in locomotor and explorative behavior (Malek et al., 2003). Hsp70 is upregulated in neonatal rats which have inhaled $0.40 \mathrm{mM}$ FA for 30 days, leading to damage to the hippocampus, such as the loss of neurons and granule cells, and reduction in the volume of the dentate gyrus (DG) and cornu ammonis (CA) (Sarsilmaz et al., 2003; Petushok et al., 2005; Aslan et al., 2006; Sarsilmaz et al., 2007). Inhalation of FA at a concentration of $13.3 \mu \mathrm{M}$ alters the expression of mouse genes, such as N-methyl-Daspartate (NMDA) receptor subunits (NR2A and NR2B), cyclic AMP responsive elementbinding protein (CREB)-1, CREB-2, FosB $/ \triangle$ FosB, dopamine receptor subtypes (D1 and D2) and transient receptor potential vanilloid receptor (TRPV1), affecting synaptic plasticity (Ahmed et al., 2007; Lu et al., 2008). Epidemiological studies on the exposure of pathologists, embalmers, and chemical workers, have shown that increased hours of exposure to FA per day are associated with reduced performance in memory, equilibrium, and dexterity, and 
even result in damage to the central nervous system (Kilburn et al., 1987; Perna et al., 2001; $\mathrm{Yu}$ et al., 2007) and headache, eye irritation and asthma-like symptoms of wheezing and bronchoconstriction (Conaway et al., 1996).

\subsection{Endogenous formaldehyde}

\subsubsection{Source of endogenous formaldehyde}

FA is present in living organisms in three states, that is, the free-state, or reversibly or irreversibly bound to macromolecules (Zhiqian Tong, 2008). FA is involved in one-carbon metabolism and plays a role in physiological processes (Abeles R.H., 1992). Increased levels of endogenous FA are believed to be a potential risk factor for health and an indicator of either pathological processes, malnutrition or environmental contamination (Kalasz, 2003).

There are several sources of endogenous FA in living organisms, arising from enzymatic or nonenzymatic reactions (Zhiqian Tong, 2008). In plants, FA is produced as a byproduct of photosynthesis and is present at a level of $0.5-1.0 \mathrm{mM}$. After its generation, the aldehyde moiety immediately combines with L-arginine to form $\mathrm{N}(\mathrm{G})$-trihydroxymethyl-L-arginine (TriHMA) through a series of enyzmic reactions (Trezl et al., 1998).

In animals, oxidative deamination is considered to be the major source of endogenous FA (Yu et al., 2003a). One important enzyme involved in FA generation by deamination is semicarbazide-sensitive amine oxidase (SSAO). SSAO, a copper-containing enzyme, is located primarily in cardiovascular smooth muscle, cartilage and other organs including the lung, liver, duodenum, kidney, and adrenal gland, and is circulated in the blood (Morrison et al., 1996; Yu et al., 1997; Mahy et al., 2001). The main substrates of SSAO are aromatic and aliphatic amines, which are deaminated into ammonia, hydrogen peroxide and FA as final products (Mahy et al., 2001; Conklin et al., 2004). In addition, monoamine oxidase (MAO) A and B, enzymes which have a similar function of that of SSAO, also generate FA (Ramonet et al., 2003). Adrenaline, whose excretion is enhanced by stress, is deaminated by monoamine oxidase (MAO) A and forms methylamine as a product. This product can be further deaminated by SSAO, yielding FA in vivo (Yu et al., 1997). In the rat liver microsome, $\mathrm{N}$-nitrosodimethylamine can be metabolized into FA via oxidative deamination (Keefer et al., 1990).

FA is also generated in the demethylation step of methionine-homocysteine cycles. For example, demethylation of S-adenosyl-L-methionine, a methyl donor in enzymatic transmethylation reactions, generates FA (Kalasz, 2003). In addition, Generation of FA can also be achieved via demethylation of other substrates. For example, liver mitochondria produce FA by the oxidation of sarcosine methyl carbons (Abeles\&Mackenzie, 1956). In normal and leukemic human leukocytes, $\mathrm{N}^{5}$-methyltetrahydrofolate undergoes an oxidative reaction catalyzed by a reductase to form $\mathrm{N}^{5}, \mathrm{~N}^{10}$-methylenetetrahydrofolate which then spontaneously releases FA. Moreover, production of FA is higher in the lymphocytes of chronic lymphocytic leukemia patients than in those of healthy individuals (Thorndike\&Beck, 1977).

Histone demethylation is another way of generating FA in vivo (Kalasz, 2003; Ehrlich, 2009). Histone demethylases catalyze the removal of histone methyl groups at lysine or arginine residues, generating FA as a byproduct (Fang\&Tian, 2007). There are two kinds of histone demethylases, namely lysine specific demethylase 1 (LSD 1) and Jumonji C (JmjC) domain family proteins (Fang\&Tian, 2007). LSD1, a nuclear homolog of amine oxidases, functions as 
a histone demethylase and transcriptional co-repressor, catalyzing the demethylation of histone $\mathrm{H3}$ at lysine 4 and the generation of FA (Shi et al., 2004). JHDM1 (JmjC domaincontaining histone demethylase 1), an enzyme which plays a role in the demethylation of histone $\mathrm{H} 3$ at lysine 36, also releases FA as a product (Zhang et al., 2006).

Demethylation of DNA and RNA is also believed to involve FA generation. Fat mass and obesity associated enzyme (FTO), a Fe(II)-and-2-oxoglutarate-dependent oxygenase, is able to demethylate 3-methylthymine in single-stranded DNA, leading to the formation of FA (Gerken et al., 2007). In addition, human ABH2 and ABH3, homologues of E. coli AlkB, are non-Fe(II)-mediated oxidative demethylases. They are involved in catalysis, releasing the methyl carbon of DNA and RNA as FA (He et al., 2009).

Microsomal cytochrome P-450 dependent oxidation of xenobiotics such as drugs, is another demethylation reaction which results in the production of endogenous FA. In addition, endogenous FA can also come from food, such as milk, ham, sausage, potato, grape and cauliflower (Trezl et al., 1997).

\subsubsection{Analysis of endogenous formaldehyde}

A variety of methods have been established for the analysis of endogenous FA. According with the universal principle, measurements by different methods result in different values for the concentration of endogenous FA. Dimedone-14C , a reagent for radiometric analysis, can be used to estimate the FA concentration in human blood and urine. Using this method, FA levels in blood and urine have been shown to vary between 0.01-0.02 mM and 0.08-0.13 $\mathrm{mM}$, respectively (Szarvas et al., 1986). Gas chromatography (GC) has been used to compare the concentration of FA in the expired air of tumor-bearing mice (1.43-2.98 $\mu \mathrm{M})$ and control mice $(0.77-1.01 \mu \mathrm{M})$ (Shibamoto et al., 1997). The concentration of FA in urine from healthy individuals ranges from 1.89-4.81 $\mu \mathrm{M}$, as determined by gas chromatography (Takigawa et al., 2007). The level of FA in the rat brain is reported to be $0.33-30.0 \mu \mathrm{M}$, as determined by GC-MS (P. Maboudou, 2002). Using selected ion flow tube mass spectrometry (SIFT-MS), the mean values of urine FA concentrations in patients with prostate cancer and bladder cancer was shown to be $0.83 \mu \mathrm{M}$ and $2.83 \mu \mathrm{M}$, respectively, compared with $0.37 \mu \mathrm{M}$ in healthy controls (Smith et al., 1999). In another study, preconcentration of the body fluid samples rendered FA more detectable by SIFT-MS. FA concentrations in Hela S3 cervical cancer, K562 leukemia and MCF-7 breast cancer cell lines range from 1.5 to $4.0 \mu \mathrm{M}$ (Bierbaum et al., 2001). The use of high performance liquid chromatography (HPLC) combined with an electrochemical procedure is an established method for the measurement of FA in vivo (Su et al., 2011). An adduct between FA and other reagents can be selectively separated by HPLC, and then quantified by an electrochemical approach. Using this method, the FA concentration of rabbit urine was found to be about $18 \mathrm{nM}$ and that of mouse liver, kidney and brain tissues to be 63,51 and $11 \mathrm{nmol} / \mathrm{g}$ tissue, respectively (Yu et al., 2003a). Another method to determine FA in blood samples by HPLC utilizes a fluorescence assay. Derivatization of human plasma with ampicillin leads to a fluorescent adduct which can be measured with a fluorescence spectrophotometer. The FA level in human blood as determined by Fluo-HPLC is $0.04 \mathrm{mM}$ (Luo et al., 2001). Thin-layer chromatography can also be used to estimate the level of FA (Kalasz, 2003). In addition, the FA level in solid tissues such as teeth can be measured by HPLC-OPLC-MS. Results show an increase in FA level in carietic teeth in comparison to healthy teeth (Rozylo et al., 2000). 


\subsubsection{Degradation of endogenous formaldehyde}

The degradation of endogenous FA mainly occurs via enzymatic catalysis. Aldehyde dehydrogenase I, and III (ADH I, ADH III), and alcohol dehydrogenase II (ALDH II) are three important enzymes involved in these reactions (Iborra et al., 1992; Zhiqian Tong, 2008). There are five classes (I-V) of alcohol dehydrogenase located in human tissues. Transcripts of class II (ALDH II) are abundant in the liver, but low in the stomach, pancreas and small intestine (Estonius et al., 1996). It has been reported that ADH III is also present in the human brain, being distributed mainly in the dendrites and cytoplasm of cerebellar Purkinje cells. The location of ADH III in the brain contributes to defending the brain against degeneration (Mori et al., 2000; Olson et al., 2003). In addition, S-formylglutathione hydrolase, glyoxalase II and catalase also function in the degradation of FA (Zhiqian Tong, 2008).

\section{In vitro investigations}

\subsection{Low concentrations of formaldehyde promote Tau aggregation}

Neuronal Tau, an important microtubule-associated protein, functions in facilitating the assembly of microtubules and maintaining their stability (Weingarten et al., 1975; Drechsel et al., 1992). Aberrant modifications of Tau protein, such as hyperphosphorylation which induces misfolding and aggregation, lead to microtubule system damage and subsequent disturbance of axonal transport and neuronal morphogenesis (Cuenda et al., 2005; Terwel et al., 2008). Hyperphosphorylated Tau is the major component of paired helical filaments (PHFs) in neurofibrillary tangles (NFTs), an important characteristic of tauopathies which include neurodegenerative conditions such as Alzheimer's disease (Goedert et al., 1996; Hardy, 2006).

The focus of research in our group is on the relationship between FA-meditated impairments and age-related dementia. Our results showed that native Tau exhibited globules with a diameter of $9 \pm 2 \mathrm{~nm}$, while FA-treated Tau had a significantly increased diameter of $18 \pm 3 \mathrm{~nm}$ in the presence of $18.0 \mathrm{mM}$ FA. The increased diameter of Tau globules was dependent on FA concentration. The rapid onset of aggregation (within $10 \mathrm{~min}$ ) was followed by a marked increase in particle size. These results were confirmed by SDS-PAGE, where an increase in the polymer bands and a decrease in the monomer bands was seen with increasing FA concentration or time. In addition, light-scattering data (at $480 \mathrm{~nm}$ ) showed that the intensity of FA-treated Tau was considerably enhanced compared with the control, further confirming that FA induced the aggregation of Tau (Nie et al., 2005). Thus, we proposed a putative mechanism of FA-induced Tau aggregation. A formaldehyde molecule first interacts with a Tau monomer. As additional FA molecules interact with other Tau monomers, the FA molecules polymerise, finally resulting in the cross-linking of the Tau molecules (Nie et al., 2007).

The wormlike conformation of Tau at room temperature, as determined by circular dichroism (CD), is reported to have a minimal content of secondary structures (Schweers et al., 1994). It was observed that the probability of the collision of KI with Tyr residues became smaller after the aggregation of Tau, and suggesting that Tyr residues may shift to the interior of the Tau molecule during aggregation, leading to the lower availability of Tyr residues for KI. The fluorescence of 8-Anilino-1-naphthalene-sulfonic acid (ANS), a 
fluorescent probe which binds to the hydrophobic regions of proteins, was enhanced as Tau was treated with FA, demonstrating the formation of a hydrophobic core during Tau aggregation. Protease rapidly cleaved native Tau to produce fragments with an apparent molecular mass of 36-37 kDa. However, no digested fragments were observed after Tau was incubated with FA, suggesting that the cleavage sites recognized by the protease were buried in the aggregates of Tau (Nie et al., 2005). In conclusion, these reports indicate that FA is able to induce neuronal Tau to misfold, resulting in aggregation and conformational changes.

\subsection{Tau aggregates induced by formaldehyde are molten globules}

Though protein misfolding is believed to induce cellular metabolic dysfunction and even cell death, the mechanism of this phenomenon remains unclear. A number of pathological mechanisms have been proposed and can be divided into two categories: one which suggests that the products of protein misfolding initiate the "death pathway" (Lipton\&Nakamura, 2009; Gu et al., 2010), and the other which proposes that "aspecific amyloid ion channels" composed of misfolded proteins cause damage to membrane permeability and result in the disturbance of ion metabolism (Lin et al., 2001; Lal et al., 2005; Lal et al., 2007). ThT fluorescence $\left(\lambda_{\mathrm{ex}}=450 \mathrm{~nm}\right)$ and Congo Red staining (measured by light absorbance at $400 \mathrm{~nm}-600 \mathrm{~nm}$ ) increased markedly, indicating that Tau aggregates had features of amyloid-like protein. Using atomic force microscopy, we observed that FAinduced Tau aggregates appeared to have a "pore-like" structure with a diameter of $8.94 \pm$ $1.62 \mathrm{~nm}$ in the middle of the aggregate. In addition, when Tau was incubated without FA, it formed fibril-like or amorphous aggregates instead of "pore-like" aggregates. It should be noted that these "pore-like" aggregates were observed at a high FA concentration under the experimental conditions, and whether they exist in vivo need to be further investigated. This might provide insights into the mechanism of tauopathies which result from protein misfolding and aggregation (Naqvi et al., 2010).

\subsection{Formaldehyde-induced aggregation interferes with Tau's protection of DNA}

Many studies have shown that Tau protein is located in axons and neuronal soma and has important functions in the microtubule system as a microtubule-associated protein (Binder et al., 1985). Recent findings have demonstrated that Tau is also present in the nucleus (Loomis et al., 1990; Johnson\&Davis, 1999) and functions in the protection of DNA (Galas et al., 2011). Heat stress and oxidative stress induce the accumulation of nonphosphorylated Tau in the nuclei of neurons. These nuclear Tau accumulations display an enhanced capacity for interacting with DNA and protect DNA from damage by stress (Galas et al., 2011). Other studies have reported that nuclear Tau binds preferentially to polynucleotides of 13 bp in length, while further research has indicated that Tau binds to the minor groove of the DNA double helix and that both its proline-rich domain (PRD) and microtubulebinding domain (MTBD) contribute to its interaction with DNA. This binding protects DNA from both digestion by DNase I and damage by peroxidation (Wei et al., 2008).

Electrophoretic mobility shift assays (EMSA) showed that native Tau retarded the mobility of DNA while no retardation was observed when DNA was incubated with either Tau aggregates induced by FA, or with BSA, indicating that Tau binding to DNA is suppressed 
by aggregation. That is, the aggregation of Tau induced by FA inhibits its ability to bind to DNA and may result in the loss of Tau's protection of DNA (Hua\&He, 2002; Lu et al., 2011). These observations suggest a novel mechanism of cell death during the pathological progress of tauopathies, such as neurodegenerative conditions.

\section{In vivo investigations}

\subsection{Formaldehyde-induced aggregation of Tau can be observed in vivo}

FA induced significant aggregates in cells. Tau-1 (an antibody which recognizes Tau protein) signals confirmed that Tau forms aggregates in the presence of FA. In addition, apoptosis of HEK 293 cells transfected with tau increased, while cells transfected with a control vector showed no increase in apoptosis (Nie et al., 2007). In another study we found that FA-induced Tau aggregates promoted apoptosis in both the SH-SY5Y cell line and rat hippocampal primary cells (Nie et al., 2006). These reports indicate that Tau aggregates induced by FA lead to apoptosis.

\subsection{Formaldehyde treated mice perform abnormally in spatial reference memory tests}

Test of mice by Morris water maze showed that the latency to platform of FA-treated mice was twice as long as controls and the length of time they spent in the target quadrant was nearly half that of controls, indicating that significant impairment of spatial reference memory function occurred when mice were treated with FA for 30 days. When resveratrol $(0.5 \mathrm{mM})$, a natural FA scavenger, was administrated to mice along with FA, the FA-induced effects on learning memory were attenuated. That is, FA-administrated mice act in abnormal performance in spatial reference memory tests.

\subsection{Excess endogenous formaldehyde is positively correlated with memory decline and cognitive impairment in animals}

Since FA can pass through the blood brain barrier (Grönvall et al, 1998; Shcherbakova et al., 1986), it is necessary to detect the level of FA in the brain in order to determine the influence of FA on the central nervous system (CNS). The FA level in the brain of three types of Alzheimer's disease mouse model, 5 month-old senescence accelerated mice (SAMP8), 3 month-old APP/PS1-transgenic mice, and 6-month old APP-transgenic mice, was estimated by Fluo-HPLC to be about $0.33,0.46$ and $0.56 \mathrm{mM} / \mathrm{g}$, respectively. Concentrations of FA in the brains of these AD models were all significantly higher than their respective controls (Tong et al., 2011). In addition, FA levels in the brains of rats were inversely correlated to their behavioral performance in the Morris water maze (Tong et al., 2011). In summary, endogenous FA concentrations in the brains of AD animal models (SAMP8, APP/PS1 and APP transgenic mice) are significantly higher than their respective controls, and excess endogenous FA can induce memory decline and cognitive impairment in animals.

In addition, $\beta$-amyloid deposits, the other main characteristic of $\mathrm{AD}$ in addition to neurofibrillary tangles, increase on treatment with FA in vitro (Yu et al., 2006) and excess endogenous FA also promotes the deposition of $A \beta$ (Yu et al., 2007). Elevated levels of FA have also been detected in patients with multiple sclerosis (Khokhlov et al., 1989). 


\section{Clinical trials}

\subsection{Urine formaldehyde levels in AD patients are correlated with the degree of dementia}

The study on the relationship between urine FA level and the degree of dementia showed that the percentage of patients with mild cognitive impairment (MCI), and medium and severe dementia in which concentrations of urine FA increased compared with that of agematched healthy controls was $42 \%$ (21/50), 82.05\% (32/39) and $88.46 \%$ (46/52), respectively (Tong et al., 2011) (Weishan Wang, 2010).

These results indicate that cognitive impairments of patients with age-related dementia are probably related to endogenous FA levels, and suggest that measuring urine FA levels together with mini mental state examination (MMSE) may be a useful non-invasive method for the investigation and diagnosis of age-related dementia.

\subsection{High levels of formaldehyde are observed in the brains of AD patients}

In addition to urine samples, we also measured the FA levels in homogenates from autopsy hippocampus tissues of AD patients by Fluo-HPLC. We found significant increases in the FA concentrations in $\mathrm{AD}$ patients (about $0.081 \mathrm{mM} / \mathrm{g} ; \mathrm{n}=4$ ) compared with normal controls (about $0.047 \mathrm{mM} / \mathrm{g} ; \mathrm{n}=4$ ) (Tong et al., 2011), indicating once again that endogenous FA level in AD patients is correlated with the progress of dementia.

\section{Formaldehyde stress}

Though the concept of "formaldehyde stress" has been mentioned in studies on Methylobacterium extorquens AMI (Miller, 2009) and tuberculosis (Bottiglioni\&Sturani, 1955), the definition of "formaldehyde stress" in neural cells was first proposed by our group. Abnormal accumulation of endogenous FA can cause abnormal modifications and misfolding of proteins, resulting in neural cell responses such as DNA damage, and even cell death (Figure 1). These may lead to dysfunction of related nervous system and cognitive impairments (He et al., 2010).

\subsection{Endogenous formaldehyde overload can induce chronic impairment and sporadic age-related dementia}

Studies indicate that the level of endogenous FA in humans is maintained homeostatically (around $0.083 \mathrm{mM}$ in urine), but increases with aging. Endogenous FA levels in AD patients and $\mathrm{AD}$ mouse models are notably higher than their respective normal controls. Stress induced by excess endogenous FA leads to chronic impairments of the CNS and may contribute to age-related dementia (He et al., 2010; Hao et al., 2011).

\subsection{Putative mechanism of formaldehyde accumulation and formaldehyde stress}

As mentioned above, generation and degradation of endogenous FA mainly depends on enzymatic reactions. With aging, dysfunction of these enzymes may cause abnormalities in the formaldehyde cycle and aberrant enzymatic production of FA from endogenous and exogenous substrates results in the accumulation of FA, leading to stress and subsequent 
pathogenic neurodegeneration (Morrison et al., 1996; Tyihak et al., 1998; Kamino et al., 2000; Yu et al., 2003b; Unzeta et al., 2005; Unzeta et al., 2007). Other factors in aging can also produce excess endogenous FA. Decreased levels of glutathione (GSH) induced by oxidative stress lead to higher levels of endogenous FA (Tyihak et al., 1998; Ling et al., 2006). $\beta$-amyloid peptide, a biomarker of Alzheimer's disease, is believed to enhance ROS production and cause a decline in the activity of ALDH2, leading to the production of excess FA (Ohta\&Ohsawa, 2006). APOE $\varepsilon 4$, considered to be a risk factor of AD, can act synergistically with the deficiency of ALDH 2 to result in accumulation of FA (Ohta et al., 2008). In addition, lipid peroxidation (LPO) (Lemeshko\&Nikitchenko Iu, 1982b, a; Dahl\&Hadley, 1983; Fokin et al., 1989; Halliwell\&Chirico, 1993), abuse of drugs (for example, nicotine and cocaine) (Dahl\&Hadley, 1983), and air pollutants (for example, endrin) (Bagchi et al., 1992) can also lead to the accumulation of FA. Polymorphisms in aldehyde dehydrogenase may be correlated with the metabolism and accumulation of FA (Thomasson et al., 1991; Wang et al., 2002; Li Hai-han 2006; Yang et al., 2008). Adh3 mutant mice are more vulnerable to FA, indicating that dysfunction of this gene is related to abnormal metabolism of FA and causes severe toxicity (Duester et al., 1999).

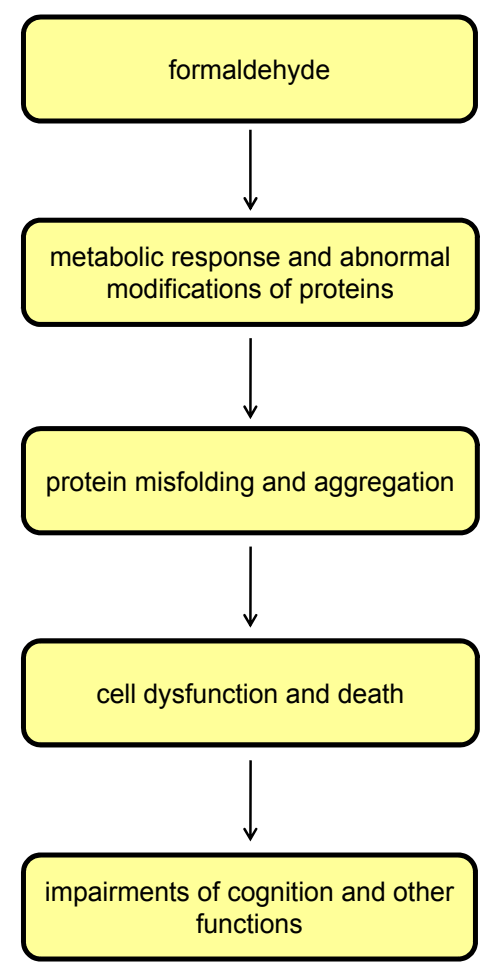

Fig. 1. A putative scheme for formaldehyde stress. Formaldehyde stress is defined as a cellular response which occurs when there is an overload of formaldehyde. Under formaldehyde stress, abnormal modifications of proteins, such as hydroxymethylation and hyperphosphorylation, is present, leading to protein misfolding and aggregation and even to cell death. 


\section{Perspective}

Since FA level is related to cognitive impairments, eliminating excess endogenous FA may become a novel therapy for age-related dementia. Trans-resveratrol (trans-3,5,4'trihydroxystilbene, Res), a phytoalexin, is a natural ingredient in grapes and various medicinal plants. Res, as a scavenger of FA, can eliminate excess FA and may prevent cells from formaldehyde stress (Tyihak et al., 1998; Marcsek et al., 2007; Marambaud et al., 2008; Gibson et al., 2009; Sun et al., 2010). Antioxidant drugs, such as vitamin E and C, can inhibit lipid peroxidation and the resultant generation of FA (Arlt S, 2001; Yu et al., 2007; Jin-xia., 2009). In addition, iron chelators can enhance the ability of cells to resist the cytotoxicity of FA (O'Brien et al., 2001).

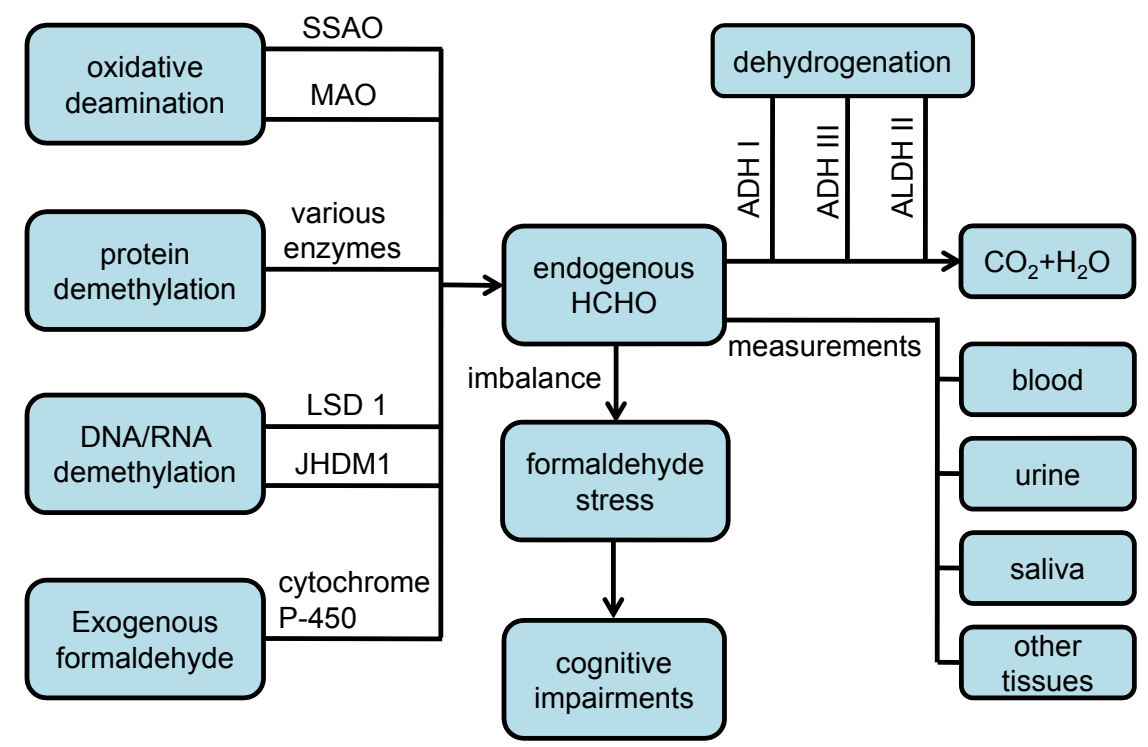

Fig. 2. Formaldehyde stress and the metabolism of endogenous formaldehyde. Endogenous formaldehyde is generated by a variety of enzymes via deamination, demethylation and other reactions. Aldehyde (alcohol) dehydrogenases are the main enzymes involved in the degradation of formaldehyde. Endogenous formaldehyde exists in all tissues such as blood, urine, saliva and brain. Aberrant metabolism causes an increase in endogenous formaldehyde and induces formaldehyde stress, resulting in the dysfunction of organs, especially cognitive impairments.

In summary, excess endogenous FA leads to "formaldehyde stress", which causes aberrant modification of protein and subsequent protein misfolding and aggregation. The aggregated protein loses its normal physiological function and initiates cell death, organ dysfunction, cognitive impairments and even age-related dementia. Elimination of excess endogenous FA may provide an approach to the therapy of dementia (Figure 2).

Though the relationship between endogenous FA and neurodegeneration has recently received considerable attention, the molecular events involved in FA-induced dementia are still unclear. Since the pathological factors in neurodegenerative diseases including 
Alzheimer's disease are complicated and synergistic, further studies should be carried out to reveal the mechanism by which FA contributes to the induction of age-related dementia.

\section{Fundings}

This work was supported by grants from the 973-Projects (2012CB911004; 2010CB912303), the Natural Scientific Foundation of China (NSFC 30970695), CAS-KSCX2-YW-R-119, KSCX2-YW-R-256 and QCAS Biotechnology Fund (GJHZ1131). The funders had no role in study design, data collection and analysis, decision to publish, or preparation of the manuscript.

\section{References}

Abeles\& Mackenzie (1956) Production of active formaldehyde in the mitochondrial oxidation of sarcosine-CD3. J Biol Chem,Vol.222,No.1,pp. 145-150,0021-9258

Abeles R.H. (1992) Chapter 25. Biochemistry, In: One Carbon Metabolism, pp. 675

Ahmed, Tsukahara, Tin Tin Win, Yamamoto, Kunugita, Arashidani\& Fujimaki (2007) Effects of low-level formaldehyde exposure on synaptic plasticity-related gene expression in the hippocampus of immunized mice. J Neuroimmunol,Vol.186,No.1-2,pp. 104$111,0165-5728$

Arlt S (2001) Lipid peroxidation as a common pathomechanism in coronary heart disease and Alzheimer disease. Z Gerontol Geriatr,Vol.34,No.6,pp. 461-465

Aslan, Songur, Tunc, Ozen, Bas, Yagmurca, Turgut, Sarsilmaz\& Kaplan (2006) Effects of formaldehyde exposure on granule cell number and volume of dentate gyrus: a histopathological and stereological study. Brain Res,Vol.1122,No.1,pp. 191-200,00068993

Bagchi, Bagchi, Hassoun\& Stohs (1992) Endrin-Induced Urinary-Excretion of Formaldehyde, Acetaldehyde, Malondialdehyde and Acetone in Rats. Toxicology,Vol.75,No.1,pp. 81-89,0300-483X

Bierbaum, Kato, Burke\& Koch (2001) Formaldehyde in human cancer cells: Detection by preconcentration-chemical ionization mass spectrometry. Analytical Chemistry, Vol.73, No.13, pp. 2992-2997,0003-2700

Binder, Frankfurter\& Rebhun (1985) The distribution of tau in the mammalian central nervous system. J Cell Biol,Vol.101,No.4,pp. 1371-1378,0021-9525

Blair, Magnani, Brand\& Wouterloot (2008) Formaldehyde in the far outer galaxy: constraining the outer boundary of the galactic habitable zone. Astrobiology, Vol.8, No.1, pp. 59-73,1531-1074

Bottiglioni\& Sturani (1955) [Formaldehyde stress and experimental tuberculosis. II. Modifications of ground substance of the connective tissue in the skin, in the specific granuloma and in the kidneys]. Arch Patol Clin Med,Vol.32,No.3,pp. 210219,0004-0142

Canuto, Levine, Augustsson, Imhoff\& Giampapa (1983) The Young Sun and the Atmosphere and Photochemistry of the Early Earth. Nature,Vol.305,No.5932,pp. 281-286,0028-0836

Conaway, Whysner, Verna\& Williams (1996) Formaldehyde mechanistic data and risk assessment: endogenous protection from DNA adduct formation. Pharmacol Ther,Vol.71,No.1-2,pp. 29-55,0163-7258 
Conklin, Cowley, Wiechmann, Johnson, Trent\& Boor (2004) Vasoactive effects of methylamine in isolated human blood vessels: role of semicarbazide-sensitive amine oxidase, formaldehyde, and hydrogen peroxide. American Journal of Physiology-Heart and Circulatory Physiology,Vol.286,No.2,pp. H667-H676,0363-6135

Cuenda, Feijoo, Campbell, Jakes\& Goedert (2005) Evidence that phosphorylation of the microtubule-associated protein Tau by SAPK4/p38 delta at Thr50 promotes microtubule assembly. Journal of Cell Science,Vol.118,No.2,pp. 397-408,0021-9533

Dahl\& Hadley (1983) Formaldehyde Production Promoted by Rat Nasal Cytochrome P-450Dependent Monooxygenases with Nasal Decongestants, Essences, Solvents, AirPollutants, Nicotine, and Cocaine as Substrates. Toxicology and Applied Pharmacology,Vol.67,No.2,pp. 200-205,0041-008X

Drechsel, Hyman, Cobb\& Kirschner (1992) Modulation of the Dynamic Instability of Tubulin Assembly by the Microtubule-Associated Protein Tau. Molecular Biology of the Cell,Vol.3,No.10,pp. 1141-1154,1059-1524

Duester, Deltour\& Foglio (1999) Metabolic deficiencies in alcohol dehydrogenase Adh1, Adh3, and Adh4 null mutant mice - Overlapping roles of Adh1 and Adh4 in ethanol clearance and metabolism of retinol to retinoic acid. Journal of Biological Chemistry,Vol.274,No.24,pp. 16796-16801,0021-9258

Ehrlich (2009) DNA hypomethylation in cancer cells. Epigenomics,Vol.1,No.2,pp. 239259,1750-1911

Estonius, Svensson\& Hoog (1996) Alcohol dehydrogenase in human tissues: localisation of transcripts coding for five classes of the enzyme. FEBS Lett,Vol.397,No.2-3,pp. 338$342,0014-5793$

Fang\& Tian (2007) Current perspectives on histone demethylases. Acta Biochimica Et Biophysica Sinica,Vol.39,No.2,pp. 81-88,1672-9145

Fokin, Ponomareva, Orlov, Liderman\& Erin (1989) [The relationship of the electrical reactions of the brain to lipid peroxidation processes in pathological aging]. Biull Eksp Biol Med,Vol.107,No.6,pp. 682-684,0365-9615

Fujimaki, Kawagoe, Bissonnette\& Befus (1992) Mast cell response to formaldehyde. 1. Modulation of mediator release. Int Arch Allergy Immunol,Vol.98,No.4,pp. 324$331,1018-2438$

Galas, Sultan, Nesslany, Violet, Begard, Loyens, Talahari, Mansuroglu, Marzin, Sergeant, Humez, Colin, Bonnefoy\& Buee (2011) Nuclear Tau, a Key Player in Neuronal DNA Protection. Journal of Biological Chemistry,Vol.286,No.6,pp. 4566-4575,0021-9258

Gerken, Girard, Tung, Webby, Saudek, Hewitson, Yeo, McDonough, Cunliffe, McNeill, Galvanovskis, Rorsman, Robins, Prieur, Coll, Ma, Jovanovic, Farooqi, Sedgwick, Barroso, Lindahl, Ponting, Ashcroft, O'Rahilly\& Schofield (2007) The obesityassociated FTO gene encodes a 2-oxoglutarate-dependent nucleic acid demethylase. Science,Vol.318,No.5855,pp. 1469-1472,1095-9203

Gibson, Karuppagounder, Pinto, Xu, Chen\& Beal (2009) Dietary supplementation with resveratrol reduces plaque pathology in a transgenic model of Alzheimer's disease. Neurochemistry International,Vol.54,No.2,pp. 111-118,0197-0186

Grönvall , Garpenstrand, Oreland, Ekblom. (1998). Autoradiographic imaging of formaldehyde adducts in mice: possible relevance for vascular damage in diabetes. Life Sci. No.63, pp. 759-768.

Goedert, Jakes, Spillantini, Hasegawa, Smith\& Crowther (1996) Assembly of microtubuleassociated protein tau into Alzheimer-like filaments induced by sulphated glycosaminoglycans. Nature,Vol.383,No.6600,pp. 550-553,0028-0836 
Gu, Nakamura\& Lipton (2010) Redox Reactions Induced by Nitrosative Stress Mediate Protein Misfolding and Mitochondrial Dysfunction in Neurodegenerative Diseases. Molecular Neurobiology,Vol.41,No.2-3,pp. 55-72,0893-7648

Halliwell\& Chirico (1993) Lipid peroxidation: its mechanism, measurement, and significance. Am J Clin Nutr,Vol.57,No.5 Suppl,pp. 715S-724S; discussion 724S-725S, 0002-9165

Hao, Li, Cui, Li, Li, Wang \& He. Correlation of urine formaldehyde levels and mini mental state examination scores in Alzheimer's disease. Chinese Journal of Gerontology, 2011, Vol.31, No.18, pp.3442-3444, 1005-9202

Hardy (2006) A hundred years of Alzheimer's disease research. Neuron,Vol.52,No.1,pp. 313,0896-6273

He, Yi\& Yang (2009) A Non-Heme Iron-Mediated Chemical Demethylation in DNA and RNA. Accounts of Chemical Research,Vol.42,No.4,pp. 519-529,0001-4842

He, Lu\& Miao (2010) Formaldehyde stress. Sci China Life Sci,Vol.53,No.12,pp. 1399$1404,1869-1889$

Naqvi, Wang, Miao \& He (2010) Pore-like Aggregates of Tau Protein Induced by Formaldehyde. Progress in Biochemistry and Biophysics,Vol.37, No.11, pp. 1195-1203, 1000-3282

Nie, Wang, Liu, Perrett \& He (2006) Amyloid-like aggregates of neuronal tau are induced by formaldehyde exposure and promote apoptosis of neuronal cells. BMC Neurosci, Vol.8, No.9

Nie, Wei, Chen, Liu, Dui, Liu, Davies, Tendler \& He (2007) Formaldehyde at Low Concentration Induces Protein Tau into Globular Amyloid-Like Aggregates In Vitro and In Vivo. Plos One,Vol.2,No.7,pp.,1932-6203

Tong, Zhang, Luo, Wang, Li, Li, Luo, Lu, Zhou, Wan \& He (2011) Urine formaldehyde level is inversely correlated to mini mental state examination scores in senile dementia. Neurobiology of Aging,Vol.32,No.1,pp. 31-41,0197-4580

Hua\& He (2002) Effect of phosphorylation and aggregation on tau binding to DNA. Protein and Peptide Letters, Vol.9,No.4,pp. 349-357,0929-8665

Iborra, Renau-Piqueras, Portoles, Boleda, Guerri\& Pares (1992) Immunocytochemical and biochemical demonstration of formaldhyde dehydrogenase (class III alcohol dehydrogenase) in the nucleus. Journal of Histochemistry \& Cytochemistry, Vol.40, No.12, pp. 1865-1878,0022-1554

Jin-xia. (2009) Effect of vitamin E against impairment on learning and memory ability. Modern Preventive Medicine,Vol.36,No.10,pp. 1833-1835

Johnson\& Davis (1999) The microtubule binding of tau and high molecular weight tau in apoptotic PC12 cells is impaired because of altered phosphorylation. Journal of Biological Chemistry,Vol.274,No.50,pp. 35686-35692,0021-9258

Kalapos (1999) A possible evolutionary role of formaldehyde. Exp Mol Med,Vol.31,No.1,pp. 1-4,1226-3613

Kalasz (2003) Biological role of formaldehyde, and cycles related to methylation, demethylation, and formaldehyde production. Mini Rev Med Chem,Vol.3,No.3,pp. 175-192,1389-5575

Kamino, Nagasaka, Imagawa, Yamamoto, Yoneda, Ueki, Kitamura, Namekata, Miki\& Ohta (2000) Deficiency in mitochondrial aldehyde dehydrogenase increases the risk for late-onset Alzheimer's disease in the Japanese population. Biochem Biophys Res Commun,Vol.273,No.1,pp. 192-196,0006-291X

Kast, Toews, Rogalski\& Clark (2008) Mass spectrometric identification of formaldehydeinduced peptide modifications under in vivo protein cross-linking conditions. Analytica Chimica Acta,Vol.618,No.2,pp. 168-183,0003-2670 
Keefer, Kroeger-Koepke, Ishizaki, Michejda, Saavedra, Hrabie, Yang\& Roller (1990) Stereoselectivity in the microsomal conversion of N-nitrosodimethylamine to formaldehyde. Chem Res Toxicol,Vol.3,No.6,pp. 540-544,0893-228X

Khokhlov, Zavalishin, Savchenko Iu\& Dziuba (1989) [Disorders of formaldehyde metabolism and its metabolic precursors in patients with multiple sclerosis]. $\mathrm{Zh}$ Nevropatol Psikhiatr Im S S Korsakova,Vol.89,No.2,pp. 45-48,0044-4588

Kilburn (1994) Neurobehavioral impairment and seizures from formaldehyde. Arch Environ Health,Vol.49,No.1,pp. 37-44,0003-9896

Kilburn, Warshaw\& Thornton (1987) Formaldehyde impairs memory, equilibrium, and dexterity in histology technicians: effects which persist for days after exposure. Arch Environ Health,Vol.42,No.2,pp. 117-120,0003-9896

Lal, Lin\& Quist (2007) Amyloid beta ion channel: 3D structure and relevance to amyloid channel paradigm. Biochim Biophys Acta,Vol.1768,No.8,pp. 1966-1975,0006-3002

Lal, Quist, Doudevski, Lin, Azimova, Ng, Frangione, Kagan\& Ghiso (2005) Amyloid ion channels: A common structural link for protein-misfolding disease. Proceedings of the National Academy of Sciences of the United States of America,Vol.102,No.30,pp. 10427-10432,0027-8424

Lemeshko\& Nikitchenko Iu (1982a) [Lipid peroxidation of myocardial membranes and its regulation during aging]. Biull Eksp Biol Med,Vol.94,No.11,pp. 12-14,0365-9615

Lemeshko\& Nikitchenko Iu (1982b) [Lipid peroxidation in rat liver mitochondria in aging and in hyperthyroidism]. Biokhimiia,Vol.47,No.5,pp. 752-759,0320-9725

Li Hai-han (2006) Polymorphisms of aldehyde and alcohol dehydrogenase genes associated with susceptibility to trichloroethylene-induced medicamentosa-like dermatitis. Journal of Hygiene Research,Vol.35,No.2,pp. 149-151

Lin, Bhatia\& Lal (2001) Amyloid beta protein forms ion channels: implications for Alzheimer's disease pathophysiology. FASEB J,Vol.15,No.13,pp. 2433-2444,1530-6860

Ling, Zhu\& Carvey (2006) Age-related changes in glutathione and glutathione-related enzymes in rat brain. Brain Research,Vol.1090,No.35-44,0006-8993

Lipton\& Nakamura (2009) Cell death: protein misfolding and neurodegenerative diseases. Apoptosis,Vol.14,No.4,pp. 455-468,1360-8185

Loomis, Howard, Castleberry\& Binder (1990) Identification of Nuclear Tau-Isoforms in Human Neuroblastoma-Cells. Proceedings of the National Academy of Sciences of the United States of America,Vol.87,No.21,pp. 8422-8426,0027-8424

$\mathrm{Lu}$, Miao, Pan \& He. Formaldehyde-mediated hyperphosphorylation disturbs the interaction between Tau protein and DNA. Prog Biochem Biophys, 2011. doi: 10.3724/SP.J.1206.2011.00451

$\mathrm{Lu}, \mathrm{Li}$, Qiao, Yan\& Yang (2008) Effect of inhaled formaldehyde on learning and memory of mice. Indoor Air,Vol.18,No.2,pp. 77-83,1600-0668

Luo, Li, Zhang\& Ang (2001) Determination of formaldehyde in blood plasma by highperformance liquid chromatography with fluorescence detection. Journal of Chromatography B,Vol.753,No.2,pp. 253-257,0378-4347

Mahy, Andres, Lizcano, Rodriguez, Romera\& Unzeta (2001) Tissue activity and cellular localization of human semicarbazide-sensitive amine oxidase. Journal of Histochemistry \& Cytochemistry,Vol.49,No.2,pp. 209-217,0022-1554

Malek, Moritz\& Fanghanel (2003) Formaldehyde inhalation \& open field behaviour in rats. Indian J Med Res,Vol.118,No.90-96,0971-5916

Marambaud, Vingtdeux, Dreses-Werringloer, Zhao\& Davies (2008) Therapeutic potential of resveratrol in Alzheimer's disease. Bmc Neuroscience,Vol.9,No.,1471-2202 
Marcsek, Kocsis, Szende\& Tompa (2007) Effect of formaldehyde and resveratrol on the viability of Vero, HepG2 and MCF-7 cells. Cell Biology International,Vol.31,No.10,pp. 1214-1219,1065-6995

Metz, Kersten, Hoogerhout, Brugghe, Timmermans, de Jong, Meiring, ten Hove, Hennink, Crommelin\& Jiskoot (2004) Identification of formaldehyde-induced modifications in proteins: reactions with model peptides. J Biol Chem,Vol.279,No.8,pp. 6235$6243,0021-9258$

Miller (1953) A production of amino acids under possible primitive earth conditions. Science,Vol.117,No.3046,pp. 528-529,0036-8075

Miller (2009) Formaldehyde Stress Response in Methylobacterium extorquens AMI. A dissertation submitted in partial fulfillment of the requirements for the degree of Doctor of Philosophy

Mori, Haseba, Kameyama, Shimizu, Kudoh, Ohaki, Arai, Yamazaki\& Asano (2000) Histological distribution of class III alcohol dehydrogenase in human brain. Brain Research,Vol.852,No.1,pp. 186-190,0006-8993

Morrison, Smith\& Kish (1996) Brain S-Adenosylmethionine levels are severely decreased in Alzheimer's disease. Journal of Neurochemistry,Vol.67,No.3,pp. 1328-1331,0022-3042

Nakamura, Ridpath, Nakamura, Tano, Luke, Sonoda, Arakawa, Buerstedde, Gillespie, Sale, Yamazoe, Bishop, Takata, Takeda, Watanabe\& Swenberg (2007) Cells deficient in the FANC/BRCA pathway are hypersensitive to plasma levels of formaldehyde. Cancer Research,Vol.67,No.23,pp. 11117-11122,0008-5472

Nie, Zhang, Zhang\& He (2005) Changes in conformation of human neuronal tau during denaturation in formaldehyde solution. Protein Pept Lett,Vol.12,No.1,pp. 75-78,09298665

O'Brien, Teng, Beard, Pourahmad, Moridani, Easson\& Poon (2001) The formaldehyde metabolic detoxification enzyme systems and molecular cytotoxic mechanism in isolated rat hepatocytes. Chemico-Biological Interactions,Vol.130,No.1-3,pp. 285296,0009-2797

Ohta\& Ohsawa (2006) Dysfunction of mitochondria and oxidative stress in the pathogenesis of Alzheimer's disease: on defects in the cytochrome c oxidase complex and aldehyde detoxification. J Alzheimers Dis,Vol.9,No.2,pp. 155-166,1387-2877

Ohta, Ohsawa, Nishimaki, Murakami, Suzuki\& Ishikawa (2008) Age-dependent neurodegeneration accompanying memory loss in transgenic mice defective in mitochondrial aldehyde dehydrogenase 2 activity. Journal of Neuroscience, Vol.28, No.24, pp. 6239-6249,0270-6474

Olson, Galter, Carmine, Buervenich\& Duester (2003) Distribution of class I, III and IV alcohol dehydrogenase mRNAs in the adult rat, mouse and human brain. European Journal of Biochemistry,Vol.270,No.6,pp. 1316-1326,0014-2956

P. Maboudou (2002) Detection of oxidative stress. Interest of GC-MS for malondialdehyde and formaldehyde monitoring. Biomedical Chromatography,Vol.16,No.199-202

Patterson, Pateras, Grammer\& Harris (1986) Human antibodies against formaldehydehuman serum albumin conjugates or human serum albumin in individuals exposed to formaldehyde. Int Arch Allergy Appl Immunol,Vol.79,No.1,pp. 53-59,0020-5915

Perna, Bordini\& Deinzer-Lifrak (2001) A case of claimed persistent neuropsychological sequelae of chronic formaldehyde exposure: clinical, psychometric, and functional findings. Arch Clin Neuropsychol,Vol.16,No.1,pp. 33-44,0887-6177 
Petushok, Petushok, El'chaninova, Ban'kovskii\& Trebukhina (2005) [Functional activity of blood and liver cells under formaldehyde intoxication via inhalation]. Biomed Khim,Vol.51,No.1,pp. 76-80

Pinto, Gladstone\& Yung (1980) Photochemical Production of Formaldehyde in Earth's Primitive Atmosphere. Science,Vol.210,No.4466,pp. 183-185,0036-8075

Pitten, Kramer, Herrmann, Bremer\& Koch (2000) Formaldehyde neurotoxicity in animal experiments. Pathol Res Pract,Vol.196,No.3,pp. 193-198,0344-0338

Ramonet, Rodriguez, Saura, Lizcano, Romera, Unzeta, Finch, Billett\& Mahy (2003) Localization of monoamine oxidase $\mathrm{A}$ and $\mathrm{B}$ and semicarbazide-sensitive amine oxidase in human peripheral tissues. Inflammopharmacology,Vol.11,No.2,pp. 111-117,0925-4692

Rety\& Marin (1957) [Coronary manifestations with myocardial ischemia after inhalation of formaldehyde vapors]. Arch Mal Prof,Vol.18,No.3,pp. 314-315,0003-9691

Rozylo, Siembida, Nemeth, Albert\& Tyihak (2000) HPLC-OPLC-MS investigation of change of formaldehyde and its generators in human teeth of different physiological stage. Biomedical Chromatography,Vol.14,No.3,pp. 173-179,0269-3879

Sakurai\& Yanagawa (1984) Prebiotic synthesis of amino acids from formaldehyde and hydroxylamine in a modified sea medium. Orig Life,Vol.14,No.1-4,pp. 171-176,03021688

Saladino, Willey, Lechner, Grafstrom, LaVeck\& Harris (1985) Effects of formaldehyde, acetaldehyde, benzoyl peroxide, and hydrogen peroxide on cultured normal human bronchial epithelial cells. Cancer Res,Vol.45,No.6,pp. 2522-2526,0008-5472

Sarsilmaz, Songur, Akpolat, Kus, Ozen\& Zararsiz (2003) The effects of the inhaled formaldehyde during the early postnatal period in the hippocampus of rats: A morphological and immunohistochemical study. Neuroscience Research Communications,Vol.33,No.3,pp. 168-178,0893-6609

Sarsilmaz, Kaplan, Songur, Colakoglu, Aslan, Tunc, Ozen, Turgut\& Bas (2007) Effects of postnatal formaldehyde exposure on pyramidal cell number, volume of cell layer in hippocampus and hemisphere in the rat: a stereological study. Brain Res,Vol.1145,No.157-167,0006-8993

Schweers, Schonbrunnhanebeck, Marx\& Mandelkow (1994) Structural Studies of TauProtein and Alzheimer Paired Helical Filaments Show No Evidence for BetaStructure. Journal of Biological Chemistry,Vol.269,No.39,pp. 24290-24297,0021-9258

Shaham, Bomstein, Gurvich, Rashkovsky\& Kaufman (2003) DNA-protein crosslinks and p53 protein expression in relation to occupational exposure to formaldehyde. Occup Environ Med,Vol.60,No.6,pp. 403-409,1351-0711

Shcherbakova, Telpukhov, Trenin, Bashikov\& Lapkina (1986) Permeability of the BloodBrain-Barrier for Intravascular Formaldehyde. Bulletin of Experimental Biology and Medicine,Vol.102,No.11,pp. 1553-1554,0007-4888

Shi, Lan, Matson, Mulligan, Whetstine, Cole\& Casero (2004) Histone demethylation mediated by the nuclear amine oxidase homolog LSD1. Cell,Vol.119,No.7,pp. 941953,0092-8674

Shibamoto, Ebeler\& Clifford (1997) Quantitative analysis by gas chromatography of volatile carbonyl compounds in expired air from mice and human. Journal of Chromatography B,Vol.702,No.1-2,pp. 211-215,0378-4347

Smith, Spanel, Holland, Al Singary\& Elder (1999) Analysis of formaldehyde in the headspace of urine from bladder and prostate cancer patients using selected ion flow tube mass spectrometry. Rapid Communications in Mass Spectrometry,Vol.13,No.14,pp. 1354-1359,0951-4198 
Soffritti, Belpoggi, Lambertin, Lauriola, Padovani\& Maltoni (2002) Results of long-term experimental studies on the carcinogenicity of formaldehyde and acetaldehyde in rats. Ann N Y Acad Sci,Vol.982,No.87-105,0077-8923

Sokolskaya (1976) Glycine and alanine synthesis from formaldehyde and hydroxylamine in the field of ultrasound waves. Orig Life,Vol.7,No.3,pp. 183-185,0302-1688

Speit, Schmid, Neuss\& Schutz (2008) Genotoxic effects of formaldehyde in the human lung cell line A549 and in primary human nasal epithelial cells. Environ Mol Mutagen,Vol.49,No.4,pp. 300-307,0893-6692

Strubelt, Brasch, Pentz\& Younes (1990) Experimental studies on the acute cardiovascular toxicity of formalin and its antidotal treatment. J Toxicol Clin Toxicol,Vol.28,No.2,pp. 221-233,0731-3810

$\mathrm{Su}$, Wei \& He. Assay of brain endogenous formaldehyde with 2,4-dinitrophenylhydrazine through UV-HPLC. Prog Biochem Biophys, 2011. doi: 10.3724/SP.J.1206.2011.00407

Sun, Wang, Simonyi\& Sun (2010) Resveratrol as a Therapeutic Agent for Neurodegenerative Diseases. Molecular Neurobiology,Vol.41,No.2-3,pp. 375-383,0893-7648

Swenberg, Kerns, Mitchell, Gralla\& Pavkov (1980) Induction of squamous cell carcinomas of the rat nasal cavity by inhalation exposure to formaldehyde vapor. Cancer Res,Vol.40,No.9,pp. 3398-3402,0008-5472

Szarvas, Szatloczky, Volford, Trezl, Tyihak\& Rusznak (1986) Determination of Endogenous Formaldehyde Level in Human-Blood and Urine by Dimedone-C-14 Radiometric Method. Journal of Radioanalytical and Nuclear Chemistry-Letters,Vol.106,No.6,pp. 357-367,0236-5731

Takigawa, Takeuchi, Abe, Kawai, Endo, Yasugi, Endo\& Ogino (2007) Determination of formaldehyde in urine by headspace gas chromatography. Bulletin of Environmental Contamination and Toxicology,Vol.79,No.1,pp. 1-4,0007-4861

Terwel, Muyllaert, Dewachter, Borghgraef, Croes, Devijver\& Van Leuven (2008) Amyloid activates GSK-3beta to aggravate neuronal tauopathy in bigenic mice. Am J Pathol,Vol.172,No.3,pp. 786-798,0002-9440

Thomasson, Edenberg, Crabb, Mai, Jerome, Li, Wang, Lin, Lu\& Yin (1991) Alcohol and aldehyde dehydrogenase genotypes and alcoholism in Chinese men. Am J Hum Genet,Vol.48,No.4,pp. 677-681,0002-9297

Thorndike\& Beck (1977) Production of formaldehyde from N5-methyltetrahydrofolate by normal and leukemic leukocytes. Cancer Res,Vol.37,No.4,pp. 1125-1132,0008-5472

Thrasher, Broughton\& Madison (1990) Immune activation and autoantibodies in humans with long-term inhalation exposure to formaldehyde. Arch Environ Health,Vol.45,No.4,pp. 217-223,0003-9896

Trezl, Hullan, Szarvas, Csiba\& Szende (1998) Determination of endogenous formaldehyde in plants (fruits) bound to L-arginine and its relation to the folate cycle, photosynthesis and apoptosis. Acta Biologica Hungarica,Vol.49,No.2-4,pp. 253263,0236-5383

Trezl, Csiba, Juhasz, Szentgyorgyi, Lombai\& Hullan (1997) Endogenous formaldehyde level of foods and its biological significance. Zeitschrift Fur Lebensmittel-Untersuchung Und-Forschung a-Food Research and Technology,Vol.205,No.4,pp. 300-304,1431-4630

Tyihak, Bocsi, Timar, Racz\& Szende (2001) Formaldehyde promotes and inhibits the proliferation of cultured tumour and endothelial cells. Cell Prolif,Vol.34,No.3,pp. 135-141,0960-7722

Tyihak, Albert, Nemeth, Katay, Kiraly-Veghely\& Szende (1998) Formaldehyde cycle and the natural formaldehyde generators and capturers. Acta Biologica Hungarica,Vol.49,No.2-4,pp. 225-238,0236-5383 
Unzeta, Sole, Boada\& Hernandez (2007) Semicarbazide-sensitive amine oxidase (SSAO) and its possible contribution to vascular damage in Alzheimer's disease. J Neural Transm,Vol.114,No.6,pp. 857-862,0300-9564

Unzeta, Hernandez, Esteban, Szabo\& Boada (2005) Human plasma semicarbazide sensitive amine oxidase (SSAO), beta-amyloid protein and aging. Neuroscience Letters,Vol.384,No.1-2,pp. 183-187,0304-3940

Wang, Nakajima, Kawamoto\& Honma (2002) Effects of aldehyde dehydrogenase-2 genetic polymorphisms on metabolism of structurally different aldehydes in human liver. Drug Metabolism and Disposition,Vol.30,No.1,pp. 69-73,0090-9556

Wei, Qu, Wang, Chen, Wang, Liu, Hua\& He (2008) Binding to the Minor Groove of the Double-Strand, Tau Protein Prevents DNA from Damage by Peroxidation. Plos One,Vol.3,No.7,pp.,1932-6203

Weingarten, Lockwood, Hwo\& Kirschner (1975) A protein factor essential for microtubule assembly. Proc Natl Acad Sci U S A,Vol.72,No.5,pp. 1858-1862,0027-8424

Weishan Wang (2010) Research on urine formaldehyde concentration in Alzheimer's disease elderly and mormal elderly. Chin J Geriatr Heart Brain Vessel Dis,Vol.12,No.721-722

Yang, Wang, Wang, Zhou, Tan, He, Xie, Li, Zheng\& Ma (2008) The association of mitochondrial aldehyde dehydrogenase gene (ALDH2) polymorphism with susceptibility to late-onset Alzheimer's disease in Chinese. Journal of the Neurological Sciences, Vol.268,No.1-2,pp. 172-175,0022-510X

Yu\& Deng (1998) Endogenous formaldehyde as a potential factor of vulnerability of atherosclerosis: involvement of semicarbazide-sensitive amine oxidase-mediated methylamine turnover. Atherosclerosis,Vol.140,No.2,pp. 357-363,0021-9150

$\mathrm{Yu}$, Lai\& Zuo (1997) Formation of formaldehyde from adrenaline in vivo; A potential risk factor for stress-related angiopathy. Neurochemical Research,Vol.22,No.5,pp. 615620,0364-3190

$\mathrm{Yu}$, Chen\& Maley (2006) Potential implications of endogenous aldehydes in beta-amyloid misfolding, oligomerization and fibrillogenesis. Journal of Neurochemistry, Vol.99, No.5, pp. 1413-1424,0022-3042

$\mathrm{Yu}$, Chen\& Kazachkov (2007) Effect of aldehydes derived from oxidative deamination and oxidative stress on beta-amyloid aggregation; pathological implications to Alzheimer's disease. Journal of Neural Transmission,Vol.114,No.6,pp. 835-839,03009564

Yu, Cauglin, Wempe\& Gubisne-Haberle (2003a) A novel sensitive high-performance liquid chromatography/electrochemical procedure for measuring formaldehyde produced from oxidative deamination of methylamine and in biological samples. Analytical Biochemistry,Vol.318,No.2,pp. 285-290,0003-2697

$\mathrm{Yu}$, Wright, Fan, Lun\& Gubisne-Harberle (2003b) Physiological and pathological implications of semicarbazide-sensitive amine oxidase. Biochimica Et Biophysica Acta-Proteins and Proteomics,Vol.1647,No.1-2,pp. 193-199,1570-9639

Zhang, Tsukada, Fang, Erdjument-Bromage, Warren, Borchers\& Tempst (2006) Histone demethylation by a family of JmjC domain-containing proteins. Nature, Vol.439, No.7078,pp. 811-816,0028-0836

Zhiqian Tong (2008) Endogenous formaldehyde and related diseases in human. Progress in Natural Science,Vol.18,No.11,pp. 1202-1210 


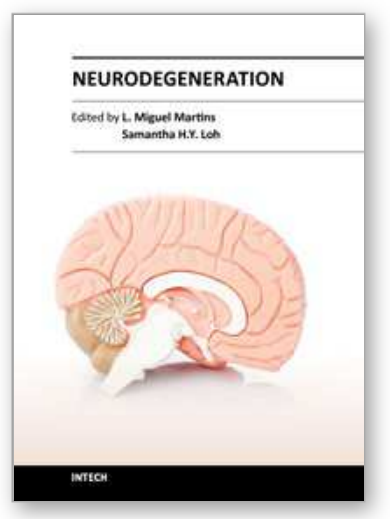

\author{
Neurodegeneration \\ Edited by Dr. L. Miguel Martins
}

ISBN 978-953-51-0502-2

Hard cover, 362 pages

Publisher InTech

Published online 11, April, 2012

Published in print edition April, 2012

Currently, the human population is on a collision course for a social and economic burden. As a consequence of changing demographics and an increase in human individuals over the age of 60, age-related neurodegenerative disorders are likely to become more prevalent. It is therefore essential to increase our understanding of such neurodegenerative disorders in order to be more pro-active in managing these diseases processes. The focus of this book is to provide a snapshot of recent advancements in the understanding of basic biological processes that modulate the onset and progression of neurodegenerative processes. This is tackled at the molecular, cellular and whole organism level. We hope that some of the recent discoveries outlined in this book will help to better define the basic biological mechanisms behind neurodegenerative processes and, in the long term, help in the development of novel therapeutic approaches.

\title{
How to reference
}

In order to correctly reference this scholarly work, feel free to copy and paste the following:

Junye Miao and Rongqiao He (2012). Chronic Formaldehyde-Mediated Impairments and Age-Related Dementia, Neurodegeneration, Dr. L. Miguel Martins (Ed.), ISBN: 978-953-51-0502-2, InTech, Available from: http://www.intechopen.com/books/neurodegeneration/chronic-formaldehyde-mediated-impairments-and-agerelated-dementia

\section{INTECH}

open science | open minds

\author{
InTech Europe \\ University Campus STeP Ri \\ Slavka Krautzeka 83/A \\ 51000 Rijeka, Croatia \\ Phone: +385 (51) 770447 \\ Fax: +385 (51) 686166 \\ www.intechopen.com
}

\author{
InTech China \\ Unit 405, Office Block, Hotel Equatorial Shanghai \\ No.65, Yan An Road (West), Shanghai, 200040, China \\ 中国上海市延安西路65号上海国际贵都大饭店办公楼405单元 \\ Phone: +86-21-62489820 \\ Fax: +86-21-62489821
}


(C) 2012 The Author(s). Licensee IntechOpen. This is an open access article distributed under the terms of the Creative Commons Attribution 3.0 License, which permits unrestricted use, distribution, and reproduction in any medium, provided the original work is properly cited. 